\title{
Eliciting cytotoxic T lymphocytes against human laryngeal cancer-derived antigens: evaluation of dendritic cells pulsed with a heat-treated tumor lysate and other antigen- loading strategies for dendritic-cell-based vaccination
}

\author{
Fan-Qin Wei ${ }^{1,2,3 \dagger}$, Wei Sun ${ }^{1 \dagger}$, Thian-Sze Wong ${ }^{4}$, Wei Gao ${ }^{4}$, Yi-Hui Wen ${ }^{1,2}$, Jia-Wei Wei ${ }^{1,2}$, Yi Wei ${ }^{1,2}$ \\ and Wei-Ping Wen ${ }^{1,2^{*}}$
}

\begin{abstract}
Background: Dendritic cells (DCs) have been used successfully in clinical pilot studies. However, tumor-specific immunity and clinical responses were only induced in certain cancer patients. It has been well documented that immunotherapy efficacy can be optimized for responses using antigen pulsing.

Methods: The human laryngeal squamous cell cancer (LSCC) cell line SNU899 was used to evaluate the in vitro anti-tumor efficacy of three different preparations of dendritic cell (DC) vaccines consisting of either whole tumor cells or their derivatives including: i) DCs pulsed with a tumor cell supernatant (DC-TCS), ii) DCs pulsed with whole-cell tumor stressed lysate (DC-TSL), and iii) DCs pulsed with irradiated tumor cells (DC-ITC).

Results: Our results showed that DC-TSL is an effective source of tumor-associated antigens (TAAs) for pulsing DCs. DC-TSL induced the highest expansion of TAA-specific T cells, the strongest Th1 cytokine response, and the most potent cytotoxic T lymphocyte (CTL) activity. DC-TCS and DC-ITC inhibited T cell activation but induced a certain extent of CTL activity.

Conclusions: These data suggest that DC-TSL is a more potent inducer of antitumor immunity against laryngeal cancer than other antigen-loading strategies using whole tumor cell materials. This strategy provides an alternative approach for DC-based immunotherapy for laryngeal cancer.
\end{abstract}

Keywords: Antigen loading, Antigen presentation, Dendritic cells, Tumor immunity, Laryngeal cancer, Tumor lysate

\footnotetext{
* Correspondence: wenwp@mail.sysu.edu.cn

${ }^{\dagger}$ Equal contributors

'Department of Otorhinolaryngology Head and Neck Surgery, the First

Affiliated Hospital of Sun Yat-sen University, 2nd Zhongshan Road 58\#, Guangzhou 510080, Guangdong, P.R. China

${ }^{2}$ Institute of Otorhinolaryngology Head and Neck Surgery, Sun Yat-sen University, 2nd Zhongshan Road 58\#, Guangzhou 510080, Guangdong, P.R.

China

Full list of author information is available at the end of the article
} 


\section{Background}

Each year, more than 500,000 cases of head and neck squamous cell carcinoma (HNSCC) are diagnosed worldwide [1]. Laryngeal squamous cell carcinoma (LSCC) accounts for a large proportion of HNSCCs [2]. Despite the rapid development of diagnosis and treatment of LSCC, including surgery, chemotherapy, and radiotherapy, the 5-year overall survival rate of LSCC remains relatively low [3]. The high rate of local recurrence and considerable mortality that accompany this malignancy mandate the development of novel therapeutic alternatives.

Immunotherapy is regarded as a promising strategy that complements current cancer therapies [4]. Dendritic cell (DC)-based vaccination trials have been performed for some advanced cancers, such as melanoma and colon, renal, and prostate cancers [5-7]. They have proven to be feasible and safe, and to elicit immunological responses [8]. Current vaccination strategies include antigen (Ag)defined vaccines (peptide, DNA, and recombinant tumor proteins) and polyvalent undefined vaccines (tumor lysate, heat shock proteins (HSPs), whole tumor cells, and whole tumor RNA) $[5,6]$. The former type of vaccine is prepared using a single tumor-associated antigen (TAA). However, its application using specific peptides is limited to patients expressing tumor-associated MHC class I restricted peptides that fail to elicit MHC class II and CD40L-mediated $\mathrm{CD} 4+\mathrm{T}$ cell helper responses. In contrast, the latter type of vaccine, generated using whole tumor cells or their derivatives, are advantageous in that they provide a full complement of TAAs, including both MHC class I and class II-restricted epitopes, thus reducing the risk of immune escape by antigen loss variants.

Whole tumor cell Ag-loading strategies for DC-based vaccination have commonly used freeze-thawed tumor cell lysates as an immunogenic source of TAAs $[9,10]$. However, DCs loaded with such lysates have provided only modest protection in various animal models $[9,11,12]$ and stimulated limited responses in a range of clinical trials $[10,13,14]$. Some studies have even shown that freeze-thawed lysates suppress DC maturation and functions in vitro, and are an ineffective loading strategy for DC therapy in vivo $[15,16]$.

To enhance antitumor immunity, studies have attempted to optimize antigen loading. Compared with ordinary lysates obtained by subjecting tumor cells to several freeze (liquid nitrogen) and thaw $\left(37{ }^{\circ} \mathrm{C}\right.$ water bath) cycles, stressed lysates prepared from heat-treated $\left(\geq 42{ }^{\circ} \mathrm{C}\right)$ tumor cells are a more effective source of TAAs for pulsing DCs. Heat-treated tumor lysate-pulsed DCs generate a stronger and broader $\mathrm{T}$ cell response against pancreatic cancer [17]. Irradiated tumor-primed DCs provide more potent protection against solid tumors, such as human melanoma [15]. Even retinoblastoma cell supernatants exert an immunostimulatory effect on DCs [18]. Because different tumor strains have various immunogenicities, it remains uncertain which Ag-loading strategy has superior efficacy for treating human laryngeal carcinoma.

In this study, we performed a detailed examination of DC phenotypes loaded with TAAs, including a tumor supernatant (TCS), tumor-stressed lysate (TSL), and irradiated tumor cells (ITC). Subsequently, we assessed TAA-specific $\mathrm{T}$ cell proliferation and Th1 cytokine production induced by these Ag-loaded DCs. Lastly, we compared the in vitro cytotoxic $\mathrm{T}$ lymphocyte (CTL) responses. Our study identified the human LSCC cell line SNU899-derived TSL as an efficacious source of TAAs for pulsing DCs to induce a more potent CTL response against laryngeal cancer.

\section{Methods \\ LSCC cell line}

SNU899 cells were kindly provided by Professor Ja-Lok $\mathrm{Ku}$ (Seoul National University College of Medicine, South Korea). Cells were maintained in RPMI-1640 containing $10 \%$ fetal bovine serum, $100 \mathrm{U} / \mathrm{ml}$ penicillin, and $100 \mu \mathrm{g} / \mathrm{ml}$ streptomycin (Sigma, St. Louis, MO, USA) in a humidified incubator at $37^{\circ} \mathrm{C}$ with $5 \% \mathrm{CO}_{2}$.

\section{Ethics statements}

The study protocol (No. 2012-349) was approved by The First Affiliated Hospital of Sun Yat-sen University Ethics Committee, and was used for research purposes only. Donor informed consent was obtained before enrollment.

\section{DCs}

Peripheral blood mononuclear cells (PBMCs) were isolated from healthy individuals by Ficoll-Hypaque density gradient centrifugation. $\mathrm{CD} 14^{+}$cells were purified using a magnetic bead-conjugated mouse anti-human CD14 monoclonal antibody (CD14 MicroBeads, Miltenyi Biotec, Bergisch Gladbach, Germany). The purity of $\mathrm{CD} 14^{+}$cells was consistently more than $95 \%$. Cells were seeded into six-well plates at $1.5 \times 10^{6}$ cells/well in $2.5 \mathrm{ml} \mathrm{RPMI-1640}$ medium supplemented with $10 \%$ heat-inactivated FBS, $50 \mathrm{ng} / \mathrm{ml}$ granulocyte macrophage-colony stimulating factor (GM-CSF, PeproTech, Rocky Hill, NJ, USA), $20 \mathrm{ng} / \mathrm{ml}$ interleukin (IL)-4 (R\&D Systems, Minneapolis, MN, USA), $100 \mathrm{U} / \mathrm{ml}$ penicillin, and $100 \mu \mathrm{g} / \mathrm{ml}$ streptomycin, and incubated at $37{ }^{\circ} \mathrm{C}$ in a humidified atmosphere with $5 \% \mathrm{CO}_{2}$. Half-volume medium changes were performed every 3 days. On day 7, DC maturation was induced by addition of $1 \mu \mathrm{g} / \mathrm{ml}$ lipopolysaccharide (LPS, Sigma) for an additional 2 days for in vitro experiments. DC phenotypes were determined by flow cytometry. 


\section{DC loading with SNU899 LSCC-derived Ags}

Day 6 DC cultures were loaded with SNU899-derived Ags using three methods. (1) Pulsing with a tumor cell supernatant prepared by seeding $4.5 \times 10^{6}$ cells in a T75 flask (Eppendorf, Hamburg, Germany) containing $4.5 \mathrm{~mL}$ completed medium for $24 \mathrm{~h}$, followed by centrifugation to remove cell debris. (2) Pulsing with a whole-cell TSL prepared at a concentration of $4.5 \times 10^{6}$ cells/well in $0.5 \mathrm{ml}$ RPMI- 1640 medium and heat-treated at $42{ }^{\circ} \mathrm{C}$ and $60{ }^{\circ} \mathrm{C}$ in sequence for $1 \mathrm{~h}$ each in a thermostatically controlled water bath, followed by immediate freezing in liquid nitrogen for $10 \mathrm{~min}$ and thawing at room temperature. This procedure was repeated four times. Cell debris were removed by centrifugation at $400 \times g$ for $20 \mathrm{~min}$. (3) Pulsing with ITC prepared at a concentration of $4.5 \times 10^{6}$ cells/well in $0.5 \mathrm{ml}$ RPMI-1640 medium and subjected to $1 \times 10^{4}$ Rads of irradiation [15]. All methods employed a tumor:DC ratio of $3: 1$ and incubation at $37^{\circ} \mathrm{C}$ for $24 \mathrm{~h}$.

\section{T cell priming by Ag-loaded autologous DCs}

Frozen PBMCs were thawed, resuspended in complete medium, and cultured overnight in a T25 flask (Eppendorf). Peripheral blood lymphocytes (PBLs) were partially purified by negative depletion from the nonadherent fraction of PBMCs after removal of monocytes by adhesion to the culture flask. PBLs were seeded in a round-bottom 96-well plate at $2 \times 10^{5}$ cells/well. The three different Ag-loaded DC preparations were added to autologous PBLs at a ratio of 1:20. After 1 week, a second identical stimulation was performed. Half of the medium was replaced with fresh medium containing $20 \mathrm{U} / \mathrm{ml} \mathrm{IL-2}$ twice per week. All experiments were performed in triplicate. PBLs alone were used as a control. The cultures were incubated at $37{ }^{\circ} \mathrm{C}$ with $5 \% \mathrm{CO}_{2} \cdot \mathrm{CD}_{4}^{+}$and $\mathrm{CD}^{+} \mathrm{T}$ cell proliferation and intracellular cytokine production in $\mathrm{CD}^{+} \mathrm{T}$ cells were assessed by flow cytometry on day 6 after the second stimulation by surface and intracellular staining.

\section{In vitro induction of TAA-specific CTL responses by tumor-derived Ag-loaded DCs}

The Ag-loaded DCs prepared by different methods were compared for their ability to stimulate CTL responses. After Ag loading and maturation, the DCs (stimulators) were added to PBLs (autologous responders to the DCs) at a ratio of 1:20 in a round bottom 96-well plate. Unpulsed mature DCs were used as a control. After 1 week, a second identical stimulation was performed. Half of the medium was replaced with fresh medium containing $20 \mathrm{U} / \mathrm{ml} \mathrm{IL-2,} \mathrm{twice} \mathrm{per} \mathrm{week.} \mathrm{On} \mathrm{day} \mathrm{6,}$ PBLs were harvested and assessed for CTL activity. The targets used for the CTL assay were SNU899-derived lysate-pulsed immature DCs autologous to the CTLs. These DC were not mature, unlike those used for CTL stimulation, because immature Ag-pulsed DCs are susceptible to CTL-mediated killing, whereas mature DCs are protected from lysis [19].

For CTL assays, targets were labeled with $5 \mu \mathrm{M}$ 5,6-carboxyfluorescein diacetate succinimidyl ester (eBioscience, San Diego, CA, USA) for $10 \mathrm{~min}$ in the dark at room temperature, and applied at an effector:target (E:T) ratio of 10:1 using $2 \times 10^{4}$ target cells/well in a round-bottom 96-well plate. In parallel, target cells were incubated alone to measure basal apoptosis. Cells were incubated for $6 \mathrm{~h}$ at $37{ }^{\circ} \mathrm{C}$ with $5 \% \mathrm{CO}_{2}$. Cytotoxicity was assessed by flow cytometry with annexin $\mathrm{V}$ and 7-aminoactinomycin $\mathrm{D}$ (7AAD) staining [20].

\section{Flow cytometry and antibodies}

DC phenotypes were determined using the following anti-human monoclonal antibodies: anti-CD1a-PE-Cy7, anti-CD83-FITC, anti-HLA-DR-eFluor 450, anti-CD80PE-Cy5, anti-CD86-PE, and anti-CD40-APC. On day 6, PBLs were harvested and stained with the following anti-human monoclonal antibodies: anti-CD3-eFluor 450, anti-CD4-FITC, and anti-CD8a- PE-Cy7 for surface staining; anti-interferon (IFN)- $\gamma$-APC-eFluor780, anti-IL-2-PE$\mathrm{Cy} 7$, and anti-tumor necrosis factor (TNF)- $\alpha$-Alexa Fluor 700 for intracellular staining. Soluble anti-CD3 (OKT3, $0.5 \mu \mathrm{g} / \mathrm{ml})$ and anti-CD28 (CD28.2, $2 \mu \mathrm{g} / \mathrm{ml})$ monoclonal antibodies were used for in vitro activation of T cells. All antibodies and isotype controls were purchased from eBioscience. Samples were analyzed using a flow cytometer (LSRFortessa, BD, Franklin Lakes, NI, USA). To examine apoptosis, target DCs were stained with APCannexin $\mathrm{V}$ and 7-AAD (BD), and analyzed using a FACSCantolI flow cytometer (BD). Data were processed using the accompanying software (FACSDiva, BD).

\section{Statistical analysis}

Experiments were repeated at least twice. Statistical analysis was carried out using SPSS version 13.0 software (IBM, Chicago, IL, USA) for Windows. Data are expressed as means and standard deviation (SD). Differences between the means were compared using Student's t-test. A difference between two variables was considered significant when the two-tailed $P$ value $<0.05$ (95\% confidence level).

\section{Results}

Effect of different Ag-loading strategies on DCs

$\mathrm{CD}_{1}{ }^{+}$cells were purified from PBMCs using CD14 MicroBeads. Upon treatment with GM-CSF and IL-4, the majority of cells formed clusters, displayed typical dendritic morphology, and became $\mathrm{CD}^{+}{ }^{+}$(94.1-99.7 \%), which are indicative of a DC phenotype. On day 6, DCs were treated for $24 \mathrm{~h}$ with SNU899-derived Ags using three strategies. Compared with control DCs, DC-TCS or DC-TSL formed larger and more aggregates, whereas the DC cell density was relatively high after co-culturing with 
ITC (Fig. 1). DC maturation was induced on day 7 by treatment with $1 \mu \mathrm{g} / \mathrm{ml}$ LPS for 2 days, and evaluated by flow cytometry (Fig. 2). DC-TSL expressed the highest levels of HLA-DR and CD86. DC-ITC also had elevated HLA-DR expression, but expressed the lowest levels of co-stimulatory molecules (CD80, CD86, and CD40). HLA-DR expression on the surface of DC-TCS remained at the same level as that in DC controls.

These data suggest that TSLs and ITC may provide much more Ags than SNU899 culture supernatant for presentation by DCs. Furthermore, tumor cell Ags may affect DC activation in response to maturation signals such as LPS. Interestingly, tumor Ags promoted cluster formation and thus may contribute to DC proliferation.

\section{Induction of TAA-specific T cell responses by Ag-loaded DCs}

Generation of TAA-specific $\mathrm{T}$ cells by the three $\mathrm{DC}$ loading strategies were compared by flow cytometry after two stimulations with Ag-loaded mature DCs. Induction of TAA-specific T cells by Ag-loaded DCs was dependent on the Ag-priming strategy, as indicated by the increased numbers of $\mathrm{CD} 4^{+}$(Fig. 3a) and $\mathrm{CD} 8^{+}$ (Fig. 3b) induced by DC-TSL, compared with DC-TCS or DC-ITC. This result strongly suggests that DC loading induces differential MHC class I and II cross-presentation of TAAs to T cells. However, this observation differs from previous reports $[15,21]$. The stressed lysis strategy of the tumor cell line SNU899 resulted in the highest efficiency of $\mathrm{T}$ cell activation, which reflected the higher levels of TAAs after loading.

\section{Analysis of TAA-specific Th1 cytokine response induced by Ag-loaded DCs}

Cytokines visualized by intracellular staining were used to confirm the effect of $\mathrm{Ag}$ priming on Th1 responses (Fig. 4). Reactive lymphocytes stimulated by Ag-loaded DC lysate showed a higher proportion of IFN- $\gamma$ and IL-2-secreting $\mathrm{CD}^{+}{ }^{+} \mathrm{T}$ cells than those stimulated by DC controls, but a lower ratio of TNF$\alpha$-secreting $\mathrm{CD}^{+}{ }^{+} \mathrm{T}$ cells. DC-TCS reduced all Th1 cytokines (IFN- $\gamma$, IL-2, and TNF- $\alpha$ ) secreted by CD $4^{+} \mathrm{T}$ cells. The irradiation strategy resulted in a decrease in the proportion of cells secreting IFN- $\gamma$ and IL-2, but increased those secreting TNF- $\alpha$ (Fig. 4a). Furthermore, significant numbers of IFN- $\gamma$ and IL-2-secreting $\mathrm{CD} 4^{+} \mathrm{T}$ cells were induced by DC-TSL (Fig. $4 \mathrm{~b}$ ), which could be attributed to the increased proportion of cytokine-secreting $\mathrm{CD} 4^{+} \mathrm{T}$ cells (Fig. 4a) and increased number of TAA-specific CD4 ${ }^{+} \mathrm{T}$ cells (Fig. 3a). However, TCS and ITC strategies inhibited the generation of Th1 cytokine-secreting CD4 ${ }^{+} \mathrm{T}$ cells.

These data suggest strongly that SNU899 cell-derived stressed lysate Ags induce a more efficient TAAspecific Th1 cytokine response, and may be the optimal Ag loading method.

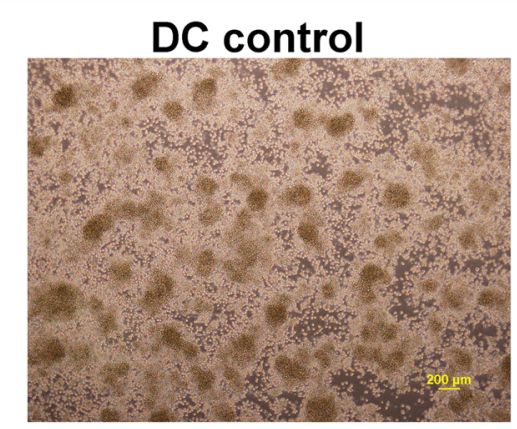

DC-TSL

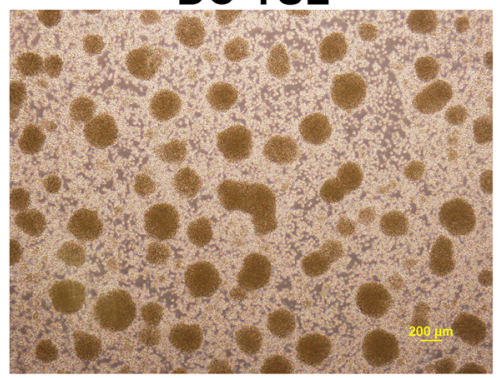

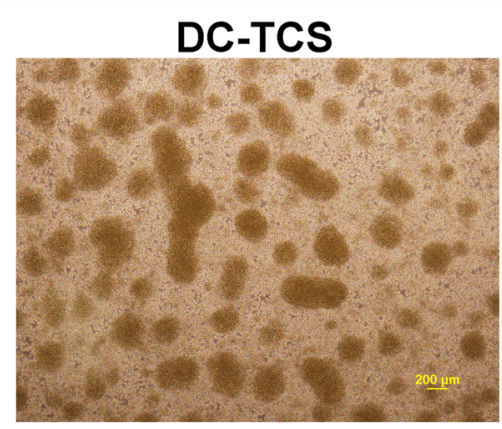

DC-ITC

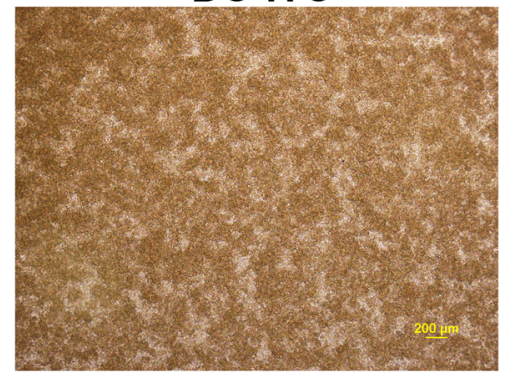

Fig. 1 Photomicrographs of DC cultures (4X). DCs cultured for 5 days were pulsed for $24 \mathrm{~h}$ with SNU899 Ags using three different methods. All methods employed a tumor:DC ratio of 3:1. Compared with the DC control $(\leq 200 \mu \mathrm{m})$, DC-TCS or DC-TSLs appeared to form larger adherent aggregates (>200 $\mu \mathrm{m})$, whereas DC-ITC had a higher density 


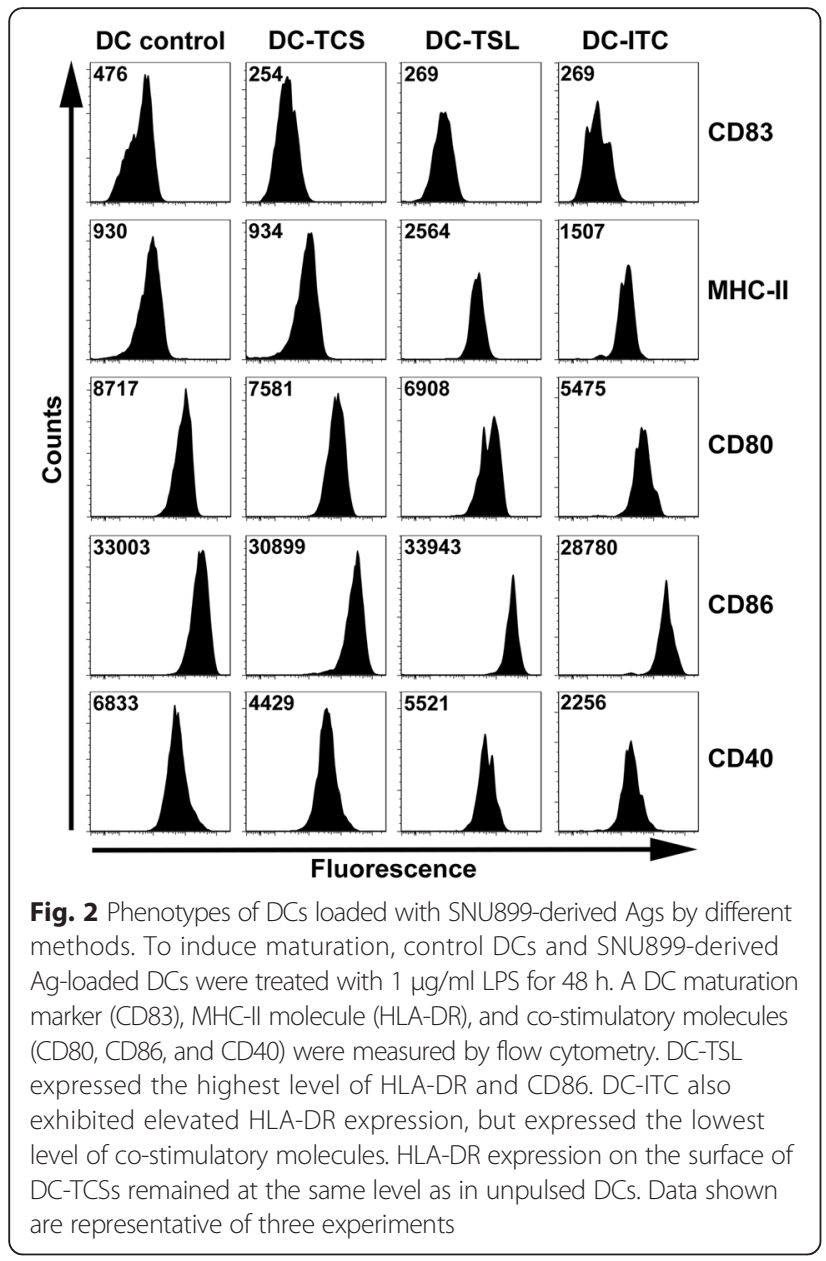

Induction of TAA-specific CTL responses

The three types of Ag-loaded DCs were used as stimulators for autologous PBLs to compare their efficacy for CTL stimulation. SNU899-derived lysate-pulsed immature DCs autologous to the CTLs were used as target cells for recognition of their MHC-antigen complexes by reactive CTLs. The ratio of apoptotic target cells was determined with flow cytometry by subtraction of basal level apoptosis. CTLs stimulated by DC-TSL resulted in a higher ratio of apoptotic target cells (Fig. 5a). Statistical analysis showed that DC-TSL were more effective at stimulating CTL responses than DC-TCS $(36.9 \pm 0.6 \%$ and $32.1 \pm 5.4 \%$, respectively; Fig. 5b). DC-ITC induced a much lower CTL response $(24.6 \pm 3.0 \%$; Fig. 5 b) compared with DC-TSL $(P=0.03)$.

\section{Discussion}

DC vaccines take advantage of the potent antigenpresenting capacity of DCs to stimulate primary and secondary $\mathrm{T}$ and $\mathrm{B}$ cell immune responses. Clinical trials have been performed for several advanced cancers such as melanoma and renal, prostate, and colon cancers, which have shown encouraging results [5-7]. DC vaccines targeting mutated proteins in the $\mathrm{p} 53$ pathway [22] and human papilloma virus peptides have been produced for the treatment of HNSCC [22, 23]. These TAA-loaded DCs stimulate immunological and clinical responses in certain patients. However, a significant proportion of patients remain unresponsive to immunomodulatory therapy.

Unlike specific TAAs, whole tumor cells or their derivatives may better apply to various tumors for which few or no defined tumor-specific antigens are available, such
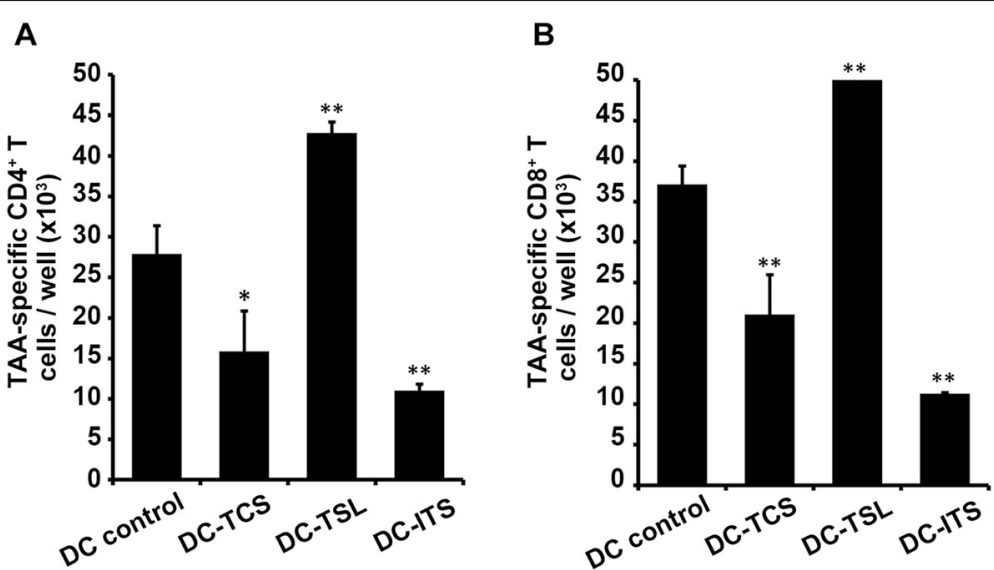

Fig. 3 Induction of TAA-specific T cell responses by DCs loaded with SNU899-derived Ags by various methods. a Induction of TAA-specific CD4 ${ }^{+}$ T cells. TAA-loaded mature DCs were added to autologous PBLs at a ratio of 1:20. On day 6 after the second stimulation, the number of CD4 ${ }^{+} T$ cells was assessed by flow cytometry. The methods used to load the DCs induced differential class II cross-presentation of TAAs to the T cells. However, the stressed lysis strategy resulted in the highest efficiency of T cell activation, reflecting a higher level of TAAs after loading. $\mathbf{b}$ Induction of TAA-specific CD8 ${ }^{+}$T cells. Similar to the cross-presentation by MHC class II, TCL-DCs were also much more efficient at cross-presentation of TAAs by MHC-I, and thus T cell activation, than DC-TCS or DC-ITC. Data are mean values \pm SD of triplicate determinations. Statistical comparisons were performed using Student's t-test. ${ }^{*} P<0.05$ vs. DC control; ${ }^{*} P<0.01$ vs. DC control 


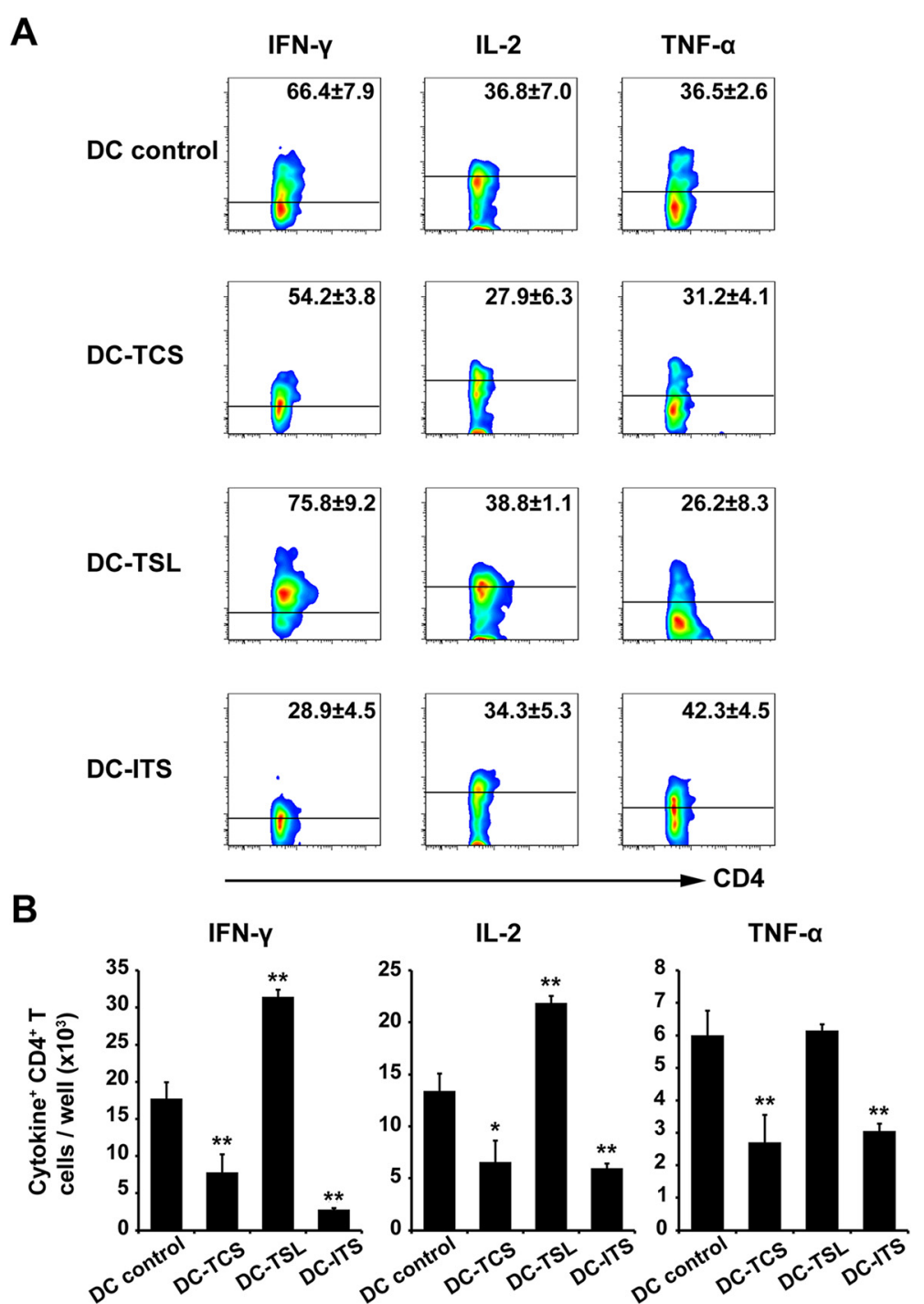

Fig. 4 Induction of TAA-specific Th1 cytokines by three DC Ag-loading strategies. DCs were pulsed with either SNU899 tumor cell supernatant, stressed lysate, or irradiated tumor cells. Autologous PBLs were stimulated twice with Ag-loaded mature DCs. On day 6 after the second stimulation, production of IFN- $\gamma$, IL-2, and TNF-a by TAA-specific CD4 ${ }^{+} T$ cells was detected by intracellular staining. a Numbers indicate the percentage of gated $\mathrm{CD}^{+} \mathrm{T}$ cells. When PBLs were stimulated by TCL-DCs, the percentage of IFN- $\gamma$ and IL-2-secreting CD4 ${ }^{+} \mathrm{T}$ cells was higher than in other groups, whereas DC-ITC induced a higher percentage of TNF-a-secreting CD4 ${ }^{+}$T cells. b Number of Th1 cytokine (IFN- $\gamma$, IL-2, and TNF-a)-positive cells were assessed by flow cytometry. Compared with the DC control, TCL-DCs stimulated an effective TAA-specific T cell response, whereas DC-TCS and DC-ITC inhibited such responses. These results clearly demonstrate the efficacy of stressed lysis as a means of tumor cell preparation for DC loading. Data are mean values \pm SD of triplicate determinations. Statistical comparisons were performed using Student's t-test. ${ }^{*} P<0.05$ vs. DC control; ${ }^{*} P<0.01$ vs. DC control

as for laryngeal cancer. Furthermore, whole tumor cell immunizations result in polyvalent stimulation of both CD4+ Th cells and CD8+ CTLs against a broad range of Ags. Therefore, DCs loaded with Ags in this manner may be used to treat laryngeal cancer.

Among the current methods for pulsing DCs with whole tumor-derived materials, tumor cell lysates, which are prepared by repeated cycles of freezing and thawing with solid debris removed by centrifugation, have been widely applied in early stage clinical trials. However, an increasing number of trials have shown that the immune response elicited by DC-TSL does not generate a sufficient antitumor potency $[10,13,14]$. Recently, several studies have demonstrated that freeze-thawed lysates suppress DC maturation and function in vitro, and are ineffective for loading DCs for therapies in vivo $[15,16]$. Our preliminary study also suggests that DCs cultured in the presence of human laryngeal cancer-derived lysates decreased surface expression of B7-1, B7-2, and $\mathrm{MHC}$ molecules, and inhibit $\mathrm{T}$ cell proliferation (data not shown). Potential explanations for these findings include the use of different tumor stains, alternate 


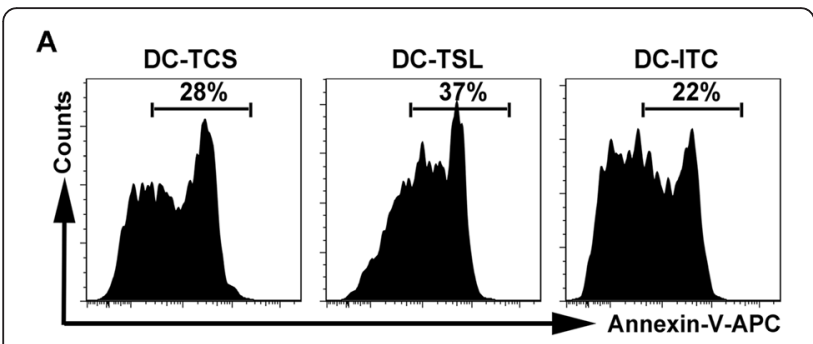

B

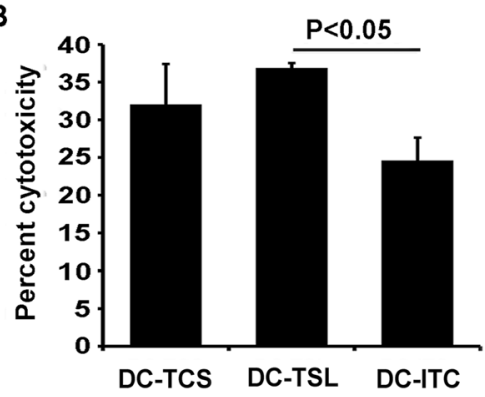

Fig. 5 Induction of TAA-specific CTL activity by three DC Ag-loading strategies. a Ag-loaded DCs were used as stimulators of autologous PBLs to compare their efficacy in CTL stimulation against Ag-pulsed target cells. PBLs and DCs were generated from a single donor. Data are from one representative experiment. b TAA-specific cytotoxicity was determined by flow cytometry. Data are the mean percentages of cytotoxicity \pm SD of triplicate determinations. TCL-DCs induced a more potent CTL response compared with DC-ITC as shown by the increased cytotoxicity from SNU899-derived Ag-pulsed autologous DCs used as targets at a 10:1 E:T. Statistical comparisons were performed using Student's t-test

vaccination schedules, and the use of DCs at various stages of maturity [10].

To elicit an effective immune response, we used three strategies for loading DCs with tumor-derived Ags and compared their ability to stimulate CTL activity. The loading strategies included using DC-TCS, DC-TSL, and DC-ITC. Our results show that human laryngeal cancerderived TSL was an effective TAA source for pulsing DCs. DC-TSL not only induced the most potent CTL activity, but also induced the strongest MHC class I TAA-specific $\mathrm{T}$ response (proliferation of TAA-specific $\mathrm{CD}^{+} \mathrm{T}$ cells), the highest expansion of TAA-specific $\mathrm{T}$ cells (based on the number of TAA-specific T cells), and the strongest Th1 cytokine response (elevated levels of IFN- $\gamma$ and IL-2 production). Interestingly, DC-TSL induced both class I and class II TAA-specific responses, suggesting that DC-TSL are capable of both class I and II cross-presentation. These results emphasize that the choice of Ag-loading strategy is critical to the strength of the immune response.

We identified alterations in the DC phenotype after treatment with tumor-derived Ags. DC-TSL expressed the highest level of HLA-DR and CD86, whereas DC-ITC also had elevated HLA-DR expression but expressed the lowest levels of co-stimulatory molecules (CD80, CD86, and CD40). HLA-DR expression on the surface of DC-TCS remained at the same level as that in DC controls. A significant body of evidence has shown that stimulating a stress response in tumor cells increases the production of HSPs, which may expand the repertoire of TAAs and enhance TAA delivery to professional antigen-presenting cells (APCs) [17, 24, 25]. Additionally, stress-induced HSPs stimulate DCs and induce APC cytokine and chemokine secretion [26-29]. Our findings support the idea that the stressed lysis strategy has advantages by providing a larger TAA repertoire. Moreover, elevation of co-stimulatory molecules such as CD86 may enhance DC capacity to prime $\mathrm{T}$ cell responses. In contrast, cell culture supernatants may not contain sufficient or adequate Ags secreted by laryngeal cancer cells. Although one study reported that DC antigen presenting function can be improved by supernatants from retinoblastoma cells [18], it is not surprising that laryngeal cancer has a distinct tumor milieu to interact with DCs. LSCC cells may evade the host immune system through manipulation of their own immunogenicity, production of immunosuppressive mediators, and promotion of immunomodulatory cell types [30-32]. Consistent with some studies [33], there was a reduction of CD80, CD86, and CD40 in DC-ITC. Various mechanisms through which intact tumor cells suppress DC functions have been described, including cytokines (e.g., TGF- $\beta$, IL-10, and vascular endothelial growth factor), ceramide [34], and other tumor-derived lipids [35]. However, a complete understanding of the mechanisms by which DC suppression functions will require additional study.

Studies have shown that $\mathrm{CD}^{+}$and Th1 cells play an important role in controlling tumor growth. For example, $\mathrm{CD}^{+} \mathrm{T}$ cells mediate antitumor immunity [36]. Th1 cells, a subset of $\mathrm{CD}^{+} \mathrm{T}$ cells, constitutively express IFN- $\gamma$ and TNF- $\alpha$, and play a role in priming tumor-specific CTLs through the release of soluble IL-2 in the proximity of CTLs [37]. In addition, induction of MHC class I tumorspecific immunity requires epitope linkage between Th1 and CTL epitopes, which is important for CTL induction [38]. In the current study, DC-TSL pulsing was the only effective method to prime $\mathrm{CD}^{+}$and $\mathrm{CD} 4^{+} \mathrm{T}$ cells. This result indicates that a TSL is not only processed for $\mathrm{MHC}$ class I presentation, but also cross-presented by the $\mathrm{MHC}$ class II pathway, consistent with the elevation of class II molecules (HLA-DR) on DC-TSL. Further experimentation showed that both the percentage and number of Th1 cells (including IFN- $\gamma$ - and IL-2-secreting cells) were increased in T cell and DC-TSL co-culture, which strongly supports the choice of TSL-pulsed as a promising CTL activator against laryngeal cancer. It is worth noting that the stronger and broader T cell response induced by DC-TSL may benefit from production of HSPs, such as HSP70 and HSP90 $[39,40]$, whose antitumor activity is exerted through 
various mechanisms. The inefficiency of DC-ITC to induce Ag-specific $\mathrm{T}$ cell responses can be explained by the inefficient cross-presentation of TAAs by DCs that express low levels of co-stimulatory molecules. Although apoptotic tumor cells induced by irradiation effectively prime APCs in vitro, they likely cannot stimulate DCs to generate an antitumor immune response in the absence of additional maturation [41].

The incompetence of DC-TCS, which express low levels of MHC molecules (e.g., HLA-DR) and maturation markers (e.g., CD83), may result from inhibition by the tumor milieu and fewer laryngeal cancer cell-secreted Ags. Although CTL activity of DC-TCS was lower than that of DC-TSL, which induced the highest as expected, there was no significant difference between them. The increased CTL activity of DC-TCS-stimulated PBLs may be due to more active natural killer and natural killer $\mathrm{T}$ cells, which comprise the majority of non-CD8 T lymphocyte effector cells [42]. Additionally, to ensure that the Ag-MHC complex was recognized by CTLs, we used Agpulsed DCs as the source of MHC-matched target cells, which may not accurately reflect tumor cell susceptibility to CTL lysis [43].

\section{Conclusions}

We demonstrate that a heat-treated TSL is an effective source of TAAs for pulsing DCs to treat human LSCC. DC-TSL induced the greatest expansion of TAA-specific T cells, the strongest Th1 cytokine response, and the most potent CTL activity, whereas DC-TCS or DC-ITC inhibited $\mathrm{T}$ cell activation and induced only a certain extent of CTL activity. Although the efficacy of this loading strategy needs to be tested further, such as in a setting whereby the CTL response could be tested using autologous laryngeal cancer cells, we have provided an encouraging alternative strategy for DC-based immunotherapy for laryngeal cancer.

\section{Abbreviations \\ DCs: dendritic cells; TAAs: tumor-associated antigens; CTL: cytotoxic T lymphocyte; HNSCC: head and neck squamous cell carcinoma; LSCC: laryngeal squamous cell carcinoma; Ag: antigen; HSPs: heat shock proteins; MHCs: major histocompatibility complexes; TSL: tumor-stressed lysate; PBMCs: peripheral blood mononuclear cells; IL: interleukin; GM-CSF: granulocyte macrophage-colony stimulating factor; LPS: lipopolysaccharide; PBLs: peripheral blood lymphocytes; SD: standard deviation; APCs: antigen-presenting cells. DC-TCS: DCs pulsed with the tumor cell supernatant; DC-TSL: DCs pulsed with the whole-cell tumor stressed lysate; DC-ITC: DCs pulsed with irradiated tumor cells.}

\section{Competing interests}

The authors declare that they have no competing interests.

\section{Authors' contributions}

WS and WPW conceived and designed the experiments. FQW, WS, TSW, WG, and YHW performed the experiments and analyzed the data. JWW performed the statistical analysis. YW made substantial contributions to collecting blood samples. FQW, WS, and WPW wrote the manuscript. All authors have read and approved the final manuscript.

\section{Acknowledgements}

We thank Dr. Li-Min Zheng for helpful discussions and critical reading of the manuscript.

\section{Funding}

This work was supported by grants from the National Natural Science Foundation of China $(81271055,81470674)$, Doctoral Foundation of Ministry of Education of China (20120171110049).

\section{Author details}

'Department of Otorhinolaryngology Head and Neck Surgery, the First Affiliated Hospital of Sun Yat-sen University, 2nd Zhongshan Road 58\#, Guangzhou 510080, Guangdong, P.R. China. ${ }^{2}$ Institute of

Otorhinolaryngology Head and Neck Surgery, Sun Yat-sen University, 2nd Zhongshan Road 58\#, Guangzhou 510080, Guangdong, P.R. China.

${ }^{3}$ Department of Otorhinolaryngology Head and Neck Surgery, the Sixth Affiliated Hospital of Sun Yat-Sen University, Yuancun Second Cross Road 26\#, Guangzhou 510655 Guangdong, P.R. China. ${ }^{4}$ Department of Surgery, The University of Hong Kong, Pokfulam Road 102\#, Hong Kong, P.R. China.

Received: 11 November 2015 Accepted: 17 January 2016

Published online: 22 January 2016

\section{References}

1. Perl G, Ben-Aharon I, Popovtzer A, Stemmer SM, Vidal L. Addition of Taxane to Induction Therapy in Head and Neck Malignancies: A Systematic Review and Meta-Analysis of Randomized Controlled Trials. Chemotherapy. 2013;59: $435-40$

2. Machiels J, Lambrecht M, Hanin F, Duprez T, Gregoire V, Schmitz S, et al. Advances in the management of squamous cell carcinoma of the head and neck. F1000Prime Rep. 2014;6:44.

3. Marioni G, Marchese-Ragona R, Cartei G, Marchese F, Staffieri A. Current opinion in diagnosis and treatment of laryngeal carcinoma. Cancer Treat Rev. 2006:32:504-15.

4. Rosenberg SA. Progress in human tumour immunology and immunotherapy. Nature. 2001:411:380-4

5. Schuler G, Schuler-Thurner B, Steinman RM. The use of dendritic cells in cancer immunotherapy. Curr Opin Immunol. 2003;15:138-47.

6. Mocellin S, Mandruzzato S, Bronte V, Lise M, Nitti D. Part I: Vaccines for solid tumours. Lancet Oncol. 2004:5:681-9.

7. Chang AE, Redman BG, Whitfield JR, Nickoloff BJ, Braun TM, Lee PP, et al. A phase I trial of tumor lysate-pulsed dendritic cells in the treatment of advanced cancer. Clin Cancer Res. 2002:8:1021-32.

8. Anguille S, Smits EL, Lion E, van Tendeloo VF, Berneman ZN. Clinical use of dendritic cells for cancer therapy. Lancet Oncol. 2014;15:E257-67.

9. Fields RC, Shimizu K, Mule JJ. Murine dendritic cells pulsed with whole tumor lysates mediate potent antitumor immune responses in vitro and in vivo. Proc Natl Acad Sci U S A. 1998;95:9482-7.

10. Nestle FO, Alijagic S, Gilliet M, Sun Y, Grabbe S, Dummer R, et al. Vaccination of melanoma patients with peptide- or tumor lysate-pulsed dendritic cells. Nat Med. 1998:4:328-32.

11. Jouanneau E, Poujol D, Gulia S, Le Mercier I, Blay JY, Belin MF, et al. Dendritic cells are essential for priming but inefficient for boosting antitumour immune response in an orthotopic murine glioma model. Cancer Immunol Immunother. 2006;55:254-67.

12. Zhang $Y Y$, Yoneyama $H$, Wang $Y$, Ishikawa S, Hashimoto S, Gao JL, et al. Mobilization of dendritic cell precursors into the circulation by administration of MIP-1 alpha in mice. J Natl Cancer Inst. 2004:96:201-9.

13. Holtl L, Zelle-Rieser C, Gander H, Papesh C, Ramoner R, Bartsch G, et al. Immunotherapy of metastatic renal cell carcinoma with tumor lysate-pulsed autologous dendritic cells. Clin Cancer Res. 2002;8:3369-76.

14. Hersey P, Menzies SW, Halliday GM, Nguyen T, Farrelly ML, DeSilva C, et al. Phase $\mathrm{I} / \mathrm{I}$ study of treatment with dendritic cell vaccines in patients with disseminated melanoma. Cancer Immunol Immunother. 2004;53:125-34.

15. Strome SE, Voss S, Wilcox R, Wakefield TL, Tamada K, Flies D, et al. Strategies for antigen loading of dendritic cells to enhance the antitumor immune response. Cancer Res. 2002;62:1884-9.

16. Hatfield P, Merrick AE, West E, O'Donnell D, Selby P, Vile R, et al. Optimization of dendritic cell loading with tumor cell lysates for cancer immunotherapy. J Imunother. 2008:31:620-32. 
17. Kim H, Choo Y, Koo T, Bang S, Oh T, Wen J, et al. Enhancement of antitumor immunity of dendritic cells pulsed with heat-treated tumor lysate in murine pancreatic cancer. Immunol Lett. 2006;103:142-8.

18. Ma J, Han HM, Ma L, Liu CZ, Xue X, Ma P, et al. The immunostimulatory effects of retinoblastoma cell supernatant on dendritic cells. Protein Cell. 2014:5:307-16

19. Nair SK, Heiser A, Boczkowski D, Majumdar A, Naoe M, Lebkowski JS, et al Induction of cytotoxic T cell responses and tumor immunity against unrelated tumors using telomerase reverse transcriptase RNA transfected dendritic cells. Nat Med. 2000;6:1011-7.

20. Lecoeur H, Fevrier M, Garcia S, Riviere Y, Gougeon ML. A novel flow cytometric assay for quantitation and multiparametric characterization of cell-mediated cytotoxicity. J Immunol Methods. 2001;253:177-87.

21. Galea-Lauri J, Wells JW, Darling D, Harrison P, Farzaneh F. Strategies for antigen choice and priming of dendritic cells influence the polarization and efficacy of antitumor T-cell responses in dendritic cell-based cancer vaccination. Cancer Immunol Immunother. 2004;53:963-77.

22. Schuler PJ, Harasymczuk M, Visus C, Deleo A, Trivedi S, Lei Y, et al. Phase I Dendritic Cell p53 Peptide Vaccine for Head and Neck Cancer. Clin Cancer Res. 2014;20:2433-44.

23. Li Q, Prince MEP, Moyer JS. Immunotherapy for head and neck squamous cell carcinoma. Oral Oncol. 2015;51:299-304.

24. Qiu J, Li G, Sui Y, Song H, Si S, Ge W. Heat-shocked tumor cell lysate-pulsed dendritic cells induce effective anti-tumor immune response in vivo. World J Gastroenterol. 2006;12:473-8.

25. Melcher A, Todryk S, Hardwick N, Ford M, Jacobson M, Vile RG. Tumor immunogenicity is determined by the mechanism of cell death via induction of heart shock protein expression. Nat Med. 1998;4:581-7.

26. Graner MW, Yi Z, Feng HP, Katsanis E. Tumor-derived chaperone-rich cell lysates are effective therapeutic vaccines against a variety of cancers. Cancer Immunol Immunother. 2003;52:226-34.

27. Srivastava PK. Immunotherapy of human cancer: lessons from mice. Nat Immunol. 2000;1:363-6.

28. Castelli C, Rivoltini L, Rini F, Belli F, Testori A, Maio M, et al. Heat shock proteins: biological functions and clinical application as personalized vaccines for human cancer. Cancer Immunol Immunother. 2004;53:227-33.

29. Li ZH, Menoret A, Srivastava P. Roles of heat-shock proteins in antigen presentation and cross-presentation. Curr Opin Immunol. 2002;14:45-51.

30. Sun W, Li WJ, Wu CY, Zhong H, Wen WP. CD45RA(-)Foxp3(high) but not CD45RA(+) Foxp3(low) suppressive T regulatory cells increased in the peripheral circulation of patients with head and neck squamous cell carcinoma and correlated with tumor progression. J Exp Clin Cancer Res. 2014;33:35

31. Sun W, Li WJ, Fu QL, Wu CY, Lin JZ, Zhu XL, et al. Functionally distinct subsets of $\mathrm{CD} 4(+)$ regulatory $T$ cells in patients with laryngeal squamous cell carcinoma are indicative of immune deregulation and disease progression. Oncol Rep. 2015;33:354-62.

32. Ferris RL. Immunology and Immunotherapy of Head and Neck Cancer. J Clin Oncol. 2015;33:3293-304.

33. Idoyaga J, Moreno J, Bonifaz L. Tumor cells prevent mouse dendritic cel maturation induced by TLR ligands. Cancer Immunol Immunother. 2007;56: 1237-50.

34. Kanto T, Kalinski P, Hunter OC, Lotze MT, Amoscato AA. Ceramide mediates tumor-induced dendritic cell apoptosis. J Immunol. 2001;167:3773-84.

35. Shurin GV, Shurin MR, Bykovskaia S, Shogan J, Lotze MT, Barksdale EM. Neuroblastoma-derived gangliosides inhibit dendritic cell generation and function. Cancer Res. 2001;61:363-9.

36. Benchetrit F, Gazagne A, Adotevi O, Haicheur N, Godard B, Badoual C, et al. Cytotoxic T lymphocytes: role in immunosurveillance and in immunotherapy. Bull Cancer. 2003;90:677-85.

37. Bennett SRM, Carbone FR, Karamalis F, Miller JFAP, Heath WR. Induction of a CD8+ cytotoxic $T$ lymphocyte response by cross-priming requires cognate CD4+ T cell help. J Exp Med. 1997;186:65-70.

38. Cassell D, Forman J. Linked recognition of helper and cytotoxic antigenic determinants for the generation of cytotoxic T lymphocytes. Ann N Y Acad Sci. 1988;532:51-60.

39. DeFillipo AM, Dai J, Li ZH. Heat shock-induced dendritic cell maturation is coupled by transient aggregation of ubiquitinated proteins independently of heat shock factor 1 or inducible heat shock protein 70 . Mol Immunol. 2004;41:785-92.

40. Basu S, Srivastava PK. Fever-like temperature induces maturation of dendritic cells through induction of hsp90. Int Immunol. 2003;15:1053-61.
41. Melcher A, Todryk S, Bateman A, Chong H, Lemoine NR, Vile RG. Adoptive transfer of immature dendritic cells with autologous or allogeneic tumor cells generates systemic antitumor immunity. Cancer Res. 1999:59:2802-5.

42. Ferlazzo G, Pack M, Thomas D, Paludan C, Schmid D, Strowig T, et al. Distinct roles of IL-12 and IL-15 in human natural killer cell activation by dendritic cells from secondary lymphoid organs. Proc Natl Acad Sci U S A. 2004;101:16606-11.

43. Galea-Lauri J, Darling D, Mufti G, Harrison P, Farzaneh F. Eliciting cytotoxic T lymphocytes against acute myeloid leukemia-derived antigens: evaluation of dendritic cell-leukemia cell hybrids and other antigen-loading strategies for dendritic cell-based vaccination. Cancer Immunol Immunother. 2002;51: 299-310.

\section{Submit your next manuscript to BioMed Central and we will help you at every step:}

- We accept pre-submission inquiries

- Our selector tool helps you to find the most relevant journal

- We provide round the clock customer support

- Convenient online submission

- Thorough peer review

- Inclusion in PubMed and all major indexing services

- Maximum visibility for your research

Submit your manuscript at www.biomedcentral.com/submit
Biomed Central 